\title{
ANÁLISE SWOT COMO FERRAMENTA ESTRATÉGICA NO PROCESSO AVALIATIVO DO CURSO DE ADMINISTRAÇÃO PÚBLICA DO IFPB
}

http://dx.doi.org/10.5902/2318133865770

\author{
Marcos Vasconcelos Paiva ${ }^{1}$ \\ Maria das Graças Gonçalves Vieira Guerra ${ }^{2}$
}

\begin{abstract}
Resumo
Investigou-se o uso da análise Swot como ferramenta estratégica de gestão para o bacharelado em Administração Pública do Instituto Federal de Educação, Ciência e Tecnologia da Paraíba, frente à aplicação do instrumento de avaliação de cursos de graduação durante a avaliação externa para a renovação de reconhecimento do curso. A pesquisa é um estudo de caso, de natureza aplicada, abordagem qualitativa e objetivo descritivo, com coleta de dados realizada por procedimento documental. Utilizou-se a análise Swot como ferramenta de identificação dos pontos fracos e fortes, por meio dos conceitos obtidos pelos indicadores de desempenho presentes no relatório de avaliação externa in loco publicado em maio de 2017.

Palavras-chave: gestão; avaliação de cursos; administração pública; IFPB.
\end{abstract}

\section{SWOT ANALYSIS AS A STRATEGIC TOOL IN THE EVALUATING PROCESS OF THE PUBLIC ADMINISTRATION COURSE OF THE IFPB}

\begin{abstract}
The research investigates the use of Swot analysis as a strategic management tool for the Bachelor of Public Administration, from the Federal Institute of Education, Science and Technology of Paraíba, in view of the application of the instrument for evaluating undergraduate courses during the external evaluation for the renewal of recognition of the course. The research is a case study, of an applied nature, qualitative approach and descriptive objective, with data collection performed by documentary procedure. The Swot analysis was used as a tool to identify weaknesses and strengths, through the concepts obtained by the performance indicators present in the external onsite evaluation published in May 2017.

Key-words: management; course evaluation; public administration; IFPB.
\end{abstract}

\footnotetext{
1 Instituto Federal de Educação, Ciência e Tecnologia da Paraíba, Brasil. E-mail: marcosvpaiva@hotmail.com.

2 Universidade Federal da Paraíba, Brasil. E-mail: gracinhavieira@yahoo.com.br. 


\section{Introdução}

O âmbito das políticas públicas nacionais voltadas para a educação nota-se uma valorização da avaliação da qualidade das instituições de ensino superior - IES - e dos cursos de graduação. Um dos destaques referentes às políticas públicas foi a criação, em 2004, do Sistema Nacional de Avaliação da Educação Superior - Sinaes. Como uma de suas principais finalidades, a avaliação proposta pelo Sinaes objetiva a melhoria da qualidade da educação superior brasileira por meio da realização de avaliações contínuas (Brasil, 2004).

Entre os processos integrados ao Sinaes está a avaliação externa in loco dos cursos de graduação. Como avaliação externa é conduzida por comissões responsáveis pela aplicação de instrumentos avaliativos, com a utilização do instrumento de avaliação de cursos de graduação - IACG - para os cursos de bacharelados, licenciaturas ou superiores em tecnologia. Os resultados obtidos com a aplicação do IACG são disponibilizados por meio de um relatório de avaliação.

Inserido a este contexto está o bacharelado em Administração Pública - BAP - curso ofertado pelo IFPB, campus João Pessoa, desde 2013, na modalidade EAD e inserido no âmbito do Sistema Universidade Aberta do Brasil por intermédio do Programa Nacional de Formação em Administração Pública (IFPB, 2017a).

Por algumas características peculiares os desafios ao BAP frente a este cenário de avaliação da qualidade da educação se tornam ainda mais complexos. Como um curso de modalidade EAD - com formatos, características e linguagens distintas do ensino presencial - a gestão do BAP necessita se adequar frente as demandas do IACG e suas atualizações, entre elas a estabelecida a partir da publicação da nota técnica n. 16/2017 do Inep, que requer a necessidade de refletir sobre ações e estratégias em potencial voltadas aos processos avaliativos.

\section{A análise Swot}

A análise Swot apresenta-se como uma ferramenta para o autoconhecimento da organização, possibilitando o monitoramento e planejamento de gestão e suas estratégias voltadas à correção das fragilidades, bem como o aprimoramento do que a empresa já faz bem (Kotler; Keller, 2012). O termo Swot procede da união de quatro palavras de origem inglesa: strengths, weakness, opportunities e threats - traduzidas, respectivamente, como forças, fraquezas, oportunidades e ameaças.

A ferramenta apresenta como proposta metodológica a classificação e análise dos dados coletados, segmentando-os entre pontos fortes e fracos de acordo com os ambientes externo e interno que envolvem as organizações públicas ou privadas. Habitualmente utilizada de forma gerencial em empresas privadas, sua aplicação em instituições públicas auxilia no planejamento estratégico e de gestão frente aos desafios impostos às organizações. Para Sant'Ana et al. (2017) a análise Swot

também se aplica a organizações públicas, já que a gestão e os resultados pretendidos pelos gestores públicos e, de alguma forma, esperados pela população, sofrem impacto de diferentes variáveis internas e externas à organização. (p. 31) 
Sob o aspecto da divisão em ambientes, promovido pela análise Swot, o ambiente interno sofre influência direta das estratégias de gestão das organizações, considerando as variáveis de forças e fraquezas. As forças remetem às vantagens que estão sobre 0 controle direto da gestão e que competem com a realidade de outras organizações semelhantes. As fraquezas demonstram as vulnerabilidades operacionais que podem comprometer a gestão e a competitividade institucional.

O ambiente externo contém elementos que se afastam da previsibilidade ou controle da organização, sendo possível apenas a identificação de variáveis que remetem a oportunidades ou ameaças. As oportunidades são acontecimentos ou tendências externas que apresentam impactos positivos sobre a organização. As ameaças são elementos de influência negativa, a serem moderados pela organização, mas que também devem ser encarados como possíveis oportunidades latentes.

A análise Swot propicia esta interseção entre distintas variáveis da gestão, por vezes até distantes dentro da organização, mas confrontadas em uma perspectiva mais próxima considerando o seu uso no planejamento.

Como forma de organizar a avaliação dos dados, a análise Swot propõe o uso de matrizes como referência visual, permitindo a melhor compreensão e investigação sobre essas variáveis. A matriz Swot possibilita a análise panorâmica dos cenários, a compreensão global da realidade em que as IES e cursos estão inseridos e, por conseguinte, amplia as informações que irão nortear as estratégias de planejamento mais adequada à situação concreta daquela organização (Souza; Guerra, 2020).

Hofrichter (2017) evidencia que a análise Swot apresenta um sentido com maior definição quando integrada a uma estratégia global ou especificamente dentro de um contexto ou situação. De forma objetiva, "tendo em vista esses conceitos, podemos afirmar que a análise de Swot se constitui em um método de efetiva relevância na identificação das forças, fraquezas, oportunidades e ameaças em que as empresas se inserem" (Guerra; Ribeiro, 2019, p. 5).

Nesta pesquisa a escolha da análise Swot tem em vista o fator organizacional e gerencial do problema investigado, permitindo a contextualização das forças, fraquezas, ameaças e oportunidades do BAP relativa aos níveis dos conceitos obtidos em cada indicador de desempenho presente à última avaliação para o reconhecimento do curso.

A importância de descrever a aplicação da análise Swot ao BAP remete a identificar as possibilidades do uso da ferramenta sobre os desafios que o curso terá frente aos próximos ciclos avaliativos, com foco na obtenção da renovação de reconhecimento do curso, tornando-se essencial analisar, especialmente sob a perspectiva dos pontos fracos, a potencial capacidade do BAP em atender as demandas avaliativas.

\section{Matriz Swot do relatório de avaliação externa do BAP}

Como passo inicial à elaboração de uma matriz Swot para o BAP foi necessário identificar e classificar os conceitos obtidos no último relatório de avaliação externa in loco do curso, disponibilizado no e-MEC e publicado pela Comissão Própria de Avaliação do IFPB (2017b). O relatório foi elaborado em maio de 2017 com a aplicação do instrumento de avaliação de cursos do Inep, mediante a visita técnica de comissão de avaliadores responsáveis por comprovar a capacidade do bacharelado em obter 0 seu reconhecimento. 
Sob a perspectiva da análise Swot torna-se intuitivo definir - de forma estratégica que os conceitos 1 e 2 obtidos pelos indicadores de desempenho do instrumento são considerados como pontos fracos do curso, por representarem a ausência de critérios mínimos que atendam o nível de satisfação para o objeto de análise. Para o conceito 3 justifica-se a não atribuição do indicador como força, oportunidade, ameaça ou fraqueza por ponderar que este valor atende de forma suficiente aos critérios demandados, determinando o seu equilíbrio. $E$, por final, os conceitos 4 e 5 caracterizam-se como pontos fortes do curso, pois apresentam em si a confirmação de suficiência do conceito 3 acrescido de atribuições complementares.

O relatório de avaliação para o reconhecimento do BAP obteve como menor valor entre os indicadores de desempenho e dimensões o conceito 3 (IFPB, 2017b). Por essa particularidade consideraremos esse conceito como uma fraqueza ou ameaça, dentro da análise e elaboração da matriz Swot do curso. Essa configuração evidencia a necessidade de se investigar e identificar ações em potencial para a gestão do BAP, objetivando a progressão dos indicadores de conceito 3 para os conceitos 4 ou 5 , com a expectativa de mudança dos pontos fracos para pontos fortes.

É importante evidenciar a duplicidade na classificação dos indicadores de desempenho presentes no instrumento de avaliação de cursos, representando-os simultaneamente como forças e oportunidades ou fraquezas e ameaças. A caracterização mútua remete à dependência do BAP e de sua gestão em relação ao ambiente externo. Um dos fatores considerados ao BAP são as diretrizes previstas em lei, como as determinações oriundas do Sinaes e demais princípios regulatórios. Qualquer atualização dessa base legal traz à tona a necessidade de mudanças no curso, demonstrando que a autonomia de gestão está apoiada na observância à legislação pertinente. Outro fator a ser considerado no ambiente externo, para algum dos indicadores de desempenho presentes no relatório, é o contexto: as variáveis da realidade econômica e social da região onde o curso é ofertado e que instituem desafios à sua gestão.

A partir dos conceitos obtidos por cada indicador de desempenho integrados à dimensão da organização didático-pedagógica, presentes no relatório de avaliação do BAP e válidos para o novo IACG, foi possível elaborar a matriz Swot apresentada no quadro 1.

\section{Quadro 1 -}

Matriz Swot da dimensão da organização didático-pedagógica do relatório de avaliação para reconhecimento do BAP.

\section{Ambiente interno}

Fraquezas

1.18. Restrição na distribuição do material didático institucional, fornecido pelo PNAP, sendo apenas de forma digital. Apresenta limitações nos aspectos da abrangência e aprofundamento do conteúdo, apesar da indicação e uso de materiais adicionais pelos docentes. 
Forças

1.2. As políticas institucionais no âmbito do curso, relacionadas ao ensino, pesquisa e extensão, como expressas no Plano de Desenvolvimento Institucional - PDI - e o Plano Pedagógico do Curso, o PPC, são muito bem atendidas pelo BAP;

1.3. Os objetivos do curso, como consta no PPC, atendem muito bem à formação profissional do egresso, com coerência à estrutura curricular e ao contexto educacional onde a instituição se insere;

1.4. As competências do perfil profissional do egresso estão muito bem definidas no PPC e apresentam coerência com as Diretrizes Curriculares Nacionais - DCN - do BAP;

1.5. A estrutura curricular implantada no BAP contempla, muito bem, os aspectos definidos no instrumento de avaliação. Destaque ao apontamento dos discentes do curso para a realização do Trabalho de Conclusão de Curso, o TCC, em período separado das demais disciplinas;

1.6. Os conteúdos curriculares atendem, muito bem, o desenvolvimento do perfil profissional do egresso em termos de adequação de carga horária, bibliografia, abordagem de conteúdos pertinentes às políticas de educação ambiental, direitos humanos, relações étnico-raciais e história e cultura afro-brasileira, africana e indígena;

1.7. As atividades pedagógicas, presentes na metodologia implantada, apresentam muito boa consonância com as DCN no tocante à acessibilidade pedagógica e atitudinal. Destaque ao apontamento dos discentes sobre a necessidade de mais encontros presenciais e videoaulas;

1.8. O estágio curricular supervisionado está previsto no PPC e muito bem regulamentado;

1.12. As atividades complementares estão muito bem regulamentadas e se constituem com componentes do curso, conforme orientação das DCN;

1.13. O TCC está muito bem implantado como componente obrigatório do curso, conforme orientação das DCN, com as formas de apresentação, orientação e coordenação presentes em regulamento próprio. Destaque dos discentes relatando a possibilidade de realização do TCC separado de outras disciplinas;

1.14. O apoio ao discente, implementado na sede do IFPB, contempla de maneira excelente os programas extraclasse, psicopedagógico e atividades extracurriculares;

1.15. As ações decorrentes dos processos de avaliação do curso, entre elas o Exame Nacional de Desempenho dos Estudantes - ENADE - e o Conceito Preliminar de Curso - CPC - estão implementadas de forma excelente, destacadas pela atuação da CPA;

1.16. As atividades de tutoria previstas atendem muito bem às demandas didático-pedagógicas da estrutura curricular;

1.17. O uso das TIC no processo de ensino-aprendizagem permite, de maneira muito boa, a execução do PPC;

1.19. Os mecanismos de interação entre docentes, tutores e estudantes previstos atendem muito bem às propostas do curso;

1.20. De acordo com os docentes e o PPC, é possível realizar todos os procedimentos de avaliação dos processos de ensino-aprendizagem;

1.21. De acordo com a dimensão do corpo docente e considerando às condições de infraestrutura da IES, verifica-se que o número de vagas atende de maneira muito boa as condições para o e ensino e aprendizagem.

Ambiente externo

Ameaças

1.18. Dependência da elaboração dos materiais didáticos bases pelo PNAP, UAB e MEC. Apresenta limitações nos aspectos de abrangência e aprofundamento dos conteúdos.

Oportunidades

Os aspectos referentes aos indicadores 1.1, 1.2, 1.3, 1.4, 1.5, 1.6, 1.7, 1.12, 1.13, 1.14, 1.15, $1.16,1.17,1.19,1,20$ e 1.21 atendem as diretrizes previstas em lei, como as determinações oriundas das DCN, da UAB e do PNAP. O curso deve estar atento a atualização dessa base legal, para que as alterações apresentem impactos positivos à qualidade do curso.

Fonte: adaptado de IFPB, 2017b. 
O BAP obteve a quase totalidade dos indicadores de desempenho válidos sob a ótica da dimensão 1, organização didático-pedagógica, destacados no quadro 1, como forças e oportunidades. Os objetos de análise com índices 1.14 e 1.15 - apoio ao discente e ações decorrentes dos processos de avaliação do curso - obtiveram o conceito 5. Os índices 1.2, 1.3, 1.4, 1.5, 1.6, 1.7, 1.8, 1.12, 1.13, 1.16, 1.17, 1.19, 1.20 e 1.21 foram avaliados com o conceito 4. Apenas o indicador 1.18, que remete ao material didático institucional, obteve o conceito 3, considerado fraqueza ou ameaça.

Em relação ao ponto fraco do curso, de acordo com o relatório de avaliação, o material didático disponibilizado pelo BAP aos discentes refere-se à bibliografia fornecida pelo PNAP e elaborado em parceria com o MEC. Identificou-se que o material didático é acessível apenas de forma digital, atendendo de forma suficiente os aspectos presentes no PPC em relação a "acessibilidade, bibliografia adequada às exigências da formação e coerência teórica" (IFPB, 2017b, p. 11). Apesar da indicação no relatório sobre o acesso exclusivo do conteúdo de forma digital o PPC do BAP evidencia a garantia do material didático impresso aos discentes, como um procedimento de apoio psicopedagógico (IFPB, 2017a). Destaca-se, ainda, a ausência de referências ao aspecto da abrangência do conteúdo.

$\mathrm{Na}$ opinião dos discentes, registrada no relatório, destacou-se a falta de aprofundamento dos temas presentes nos materiais didáticos disponibilizados, apesar da utilização de recursos audiovisuais nas disciplinas e da indicação de materiais complementares pelos docentes. Ratifica-se, por meio das características apresentadas, a identificação do indicador de desempenho 1.18 como uma ameaça ao curso, tendo em vista a falta de controle direto da gestão do BAP sobre a elaboração e distribuição dos materiais fornecidos pelo PNAP, e como uma fraqueza, por partir do planejamento docente, em cada disciplina ofertada, a decisão e inclusão de materiais adicionais, complementando e aprofundando o conteúdo abordado aos discentes.

Em relação aos pontos fortes do curso, indicados pelas forças e oportunidades, identificou-se no relatório que os objetos mencionados no PPC do BAP, no PDI do IFPB e no relatório de autoavaliação institucional estão presentes e atendem a aspectos como as políticas institucionais, objetivos, perfil profissional do egresso, estrutura curricular, conteúdos curriculares, metodologia, número de vagas e ações decorrentes dos processos de avaliação no curso. As ações acadêmico-administrativas do BAP, referentes aos processos da autoavaliação e da avaliação externa, foram consideradas excelentes, demonstrando a presença ativa da CPA e o potencial do curso em se adequar as demandas das diretrizes do Sinaes e seus instrumentos avaliativos.

Outros pontos fortes identificados no relatório, ainda na dimensão da organização didático-pedagógica, estão os relacionados ao processo de ensino e de atividades direcionadas aos discentes, como o estágio curricular supervisionado; atividades complementares; TCC; apoio ao discente; atividades de tutoria; uso de TIC no processo ensino-aprendizagem; mecanismos de interação entre docentes, tutores e estudantes e os procedimentos de avaliação dos processos de ensino-aprendizagem. Ressalta-se que a avaliação do apoio ao discente foi considerada excelente, ratificada pela existência da Coordenação de Apoio às Pessoas com Necessidades Específicas - Coapne - na sede do curso, responsável pelo atendimento e suporte da acessibilidade com profissionais 
especializados; e pela oferta de aulas de nivelamento onde "são trabalhadas as dificuldades de aprendizado, orientação didático-metodológica, bem como auxílio para a resolução de determinadas dificuldades do dia a dia" (IFPB, 2017b, p.10).

Em relação aos conceitos obtidos pelos indicadores de desempenho integrados à dimensão do corpo docente e tutorial, integrando ao relatório de avaliação externa, e considerando as demandas válidas para o novo IACG, foi possível elaborar a matriz Swot apresentada pelo quadro 2.

\section{Quadro 2 -}

Matriz Swot da dimensão do corpo docente e tutorial do relatório de avaliação para reconhecimento do BAP.

\begin{tabular}{|l}
\hline Ambiente interno \\
\hline Fraquezas \\
\hline Não há registro de fraques. \\
\hline Forças
\end{tabular}

Forças

2.1. A atuação do Núcleo Docente Estruturante - NDE - é considerada excelente, por meio de uma análise sistêmica e global sobre os aspectos da concepção, acompanhamento, consolidação e avaliação do PPC

2.2. A atuação do coordenador é excelente, considerando, em uma análise sistêmica e global, os aspectos da gestão do curso, relação com os docentes e discentes e representatividade nos colegiados superiores

2.3. A soma da experiência profissional, de magistério superior e de gestão acadêmica do coordenador é maior ou igual a dez anos, apresentando no mínimo um ano de magistério superior;

2.5. A carga horária de coordenação de curso é igual a vinte horas semanais, sendo dedicada totalmente à coordenação;

2.6. A titulação do corpo docente do curso que possui pós-graduação stricto sensu representa $86,21 \%$ dos docentes do BAP, sendo quatorze mestres e onze doutores. O curso ainda conta com quatro especialistas;

2.8. O regime de trabalho do corpo docente do curso atende a $100 \%$ de trabalho integral na instituição;

2.9. A experiência profissional do corpo docente encontra-se entre $60 \%$ a $80 \%$ de pelo menos dois anos para bacharelados;

2.11. A experiência de magistério superior do corpo docente, de pelo menos três anos de bacharelados, possui um percentual de $93,10 \%$;

2.12. A relação entre o número de docentes e o número de vaga é de duzentas vagas para vinte e nove docentes, com 6,90 vagas por docente;

2.13. O funcionamento do colegiado de curso está institucionalizado de forma excelente, considerando os aspectos da representatividade dos segmentos, periodicidade das reuniões, registros e encaminhamento das decisões;

2.14. Pelo menos $50 \%$ dos docentes tem realizado atividades voltadas para elaboração científica, cultural, artística ou tecnológica, apresentando de sete a nove produções nos últimos três anos;

2.15. Sobre a titulação e formação do corpo de tutores do curso, o BAP apresenta $35,72 \%$ dos tutores que possuem título de mestre;

2.16. A experiência do corpo de tutores em educação a distância, de pelo menos três anos na EaD, é maior que $70 \%$;

A relação docentes e tutores - presenciais e a distância - por estudante ocorre entre quarenta e três docentes/tutores para duzentos estudantes, representando uma taxa de 3,77 alunos por docente/tutor.

Ambiente externo

Ameaças

Não há registros de ameaças

Regae: Rev. Gest. Aval. Educ. $\quad$ Santa Maria

v. 10

ก. 19

e65770, p. 1-13

2021 
Oportunidades

A atuação dos indicadores 2.1, 2.2, 2.3, 2.5, 2.6, 2.8, 2.9, 2.11, 2.12, 2.13, 2.14, 2.15, 2.16 e 2.17 atendem as determinações das DCN, da UAB e do PNAP. O curso deve estar atento a atualização dessa base legal, para que as alterações apresentem impactos positivos à qualidade do curso.

Fonte: adaptado de IFPB (2017b).

$\mathrm{Na}$ avaliação da dimensão 2, referente ao corpo docente e tutorial, todos os indicadores de desempenho válidos alcançaram resultados associados a forças e oportunidades. Desses resultados apenas três indicadores apresentaram conceito 4, representados pelos índices $2.5,2.9$ e 2.14 . Os demais objetos de análise avaliados nessa dimensão obtiveram o conceito máximo, sendo respectivamente representados pelos índices 2.1, 2.2, 2.3, 2.6, 2.8, 2.11, 2.12, 2.13, 2.15, 2.16 e 2.17.

Em referência aos pontos fortes do BAP, com análise aos objetos presentes no PPC, PDI e nas informações fornecidas pela instituição ao e-MEC, identificou-se no relatório de avaliação que as atuações do NDE e do colegiado do curso foram consideradas excelentes.

Em relação à coordenação do curso ainda se indicou a atuação com excelência do coordenador do BAP. Outro destaque é o resultado da soma da experiência profissional, de magistério superior e de gestão acadêmica do coordenador, sendo superior a dez anos: valor que permitiu o conceito máximo ao objeto de análise. A carga horária da coordenação, de vinte horas semanais, foi considerada muito boa.

Em relação aos aspectos da tutoria, a titulação e formação dos corpos de tutores do BAP apresentou uma porcentagem de $35,72 \%$ de mestres e a experiência profissional mínima de três anos em cursos EAD superior a 70\%. Ambos indicadores demonstraram uma elevada qualidade das atividades de tutoria no curso.

O corpo docente encontra-se como tópico de maior enfoque dentro da análise definida pelo relatório de avaliação. Dos indicadores de desempenho referentes à docência apenas dois foram considerados muito bons: a experiência profissional dos docentes, entre $60 \%$ a $80 \%$, de no mínimo dois anos de experiência para bacharelados, e a elaboração científica, cultural, artística ou tecnológica dos docentes, entre sete a nove produções nos últimos três anos.

Os demais indicadores do corpo docente alcançaram a excelência, caracterizados por: titulação com pós-graduação stricto sensu em $86,21 \%$; regime de trabalho integral na instituição atendido em 100\%; experiência de magistério superior com no mínimo três anos de bacharelado em $93,10 \%$; oferta de 6,90 vagas do curso por docente; e a relação de 3,77 alunos por docente e tutor do BAP. Em análise aos conceitos obtidos pelos indicadores de desempenho integrados à última dimensão avaliada - Infraestrutura - e considerados válidos ao novo IACG, constituiu-se a matriz Swot apresentada pelo quadro 3. 
Quadro 3 -

Matriz Swot da dimensão da infraestrutura do relatório de avaliação para reconhecimento do BAP.

Ambiente interno
Fraquezas
3.1. Insuficiência dos espaços de gabinetes de trabalho para professores em Tempo Integral -
TI;
3.2. Limitação no espaço de trabalho para coordenação do curso e serviços acadêmicos,
compartilhado com outros cinco cursos integrados à Unidade Acadêmica de Gestão - UAG - ao
qual o BAP está vinculado;
3.3. Insuficiência de espaço destinado à sala de professores;
3.4. Limitações nos espaços destinados às salas de aula.
Forças

3.5. O acesso dos alunos a equipamentos de informática, na sede do BAP, apresenta: quarenta laboratórios de informática, com média de vinte e dois computadores; laboratório exclusivo para EaD, com vinte computadores; e laboratório da UAG, contendo quinze computadores;

3.6. O acervo da bibliografia básica, presente na sede do curso, conta com no mínimo três títulos por unidade curricular, com proporção média de um exemplar para a faixa entre cinco a dez vagas anuais autorizadas, de cada uma das unidades curriculares, de todos os cursos que efetivamente utilizam o acervo. Encontra-se informatizada e tombada no patrimônio da IES;

3.7. Na sede do curso, o acervo da bibliografia complementar possui, pelo menos quatro títulos por unidade curricular, com dois exemplares de cada título ou com acesso virtual. A bibliografia encontra-se informatizada e tombada junto ao patrimônio da IES;

3.12. O sistema de controle de elaboração e distribuição de material didático (logística) previsto atende muito bem à demanda real;

3.21. O Comitê de Ética em Pesquisa - CEP - está devidamente instituído e consolidado no curso.

Ambiente externo

Ameaças

3.1. Dependência com o IFPB campus João Pessoa sobre a disponibilidade de espaços para a coordenação do curso;

3.2. Dependência com o IFPB campus João Pessoa sobre a disponibilidade de espaços para os docentes em Tl;

3.3. Dependência com o IFPB campus João Pessoa sobre a disponibilidade de espaços para as salas de professores;

3.4. Dependência com o IFPB campus João Pessoa e órgãos municipais sobre a disponibilidade de espaços para salas de aula na sede e polos.

\section{Oportunidades}

Os indicadores $3.5,3.6,3.7,3.12$ e 3.21 atendem as diretrizes previstas em lei, como as determinações oriundas das DCN, da UAB e do PNAP. O curso deve estar atento a atualização dessa base legal, para que as alterações apresentem impactos positivos à qualidade do curso.

Fonte: adaptado de IFPB (2017b).

Em relação à dimensão da infraestrutura, dos indicadores considerados válidos, cinco foram evidenciados como forças e oportunidades e quatro como fraquezas e ameaças. Das forças e oportunidades o indicador 3.21 foi o único objeto de análise a obter o conceito máximo, com os indicadores 3.5, 3.6, 3.7 e 3.12 avaliados com o conceito 4 . Em relação às fraquezas e ameaças os resultados foram representados pelos índices 3.1, 3.2, 3.3 e 3.4, identificados com o conceito 3. 
Em relação aos pontos fracos do BAP, ao indicador de desempenho 3.1, referente aos gabinetes de trabalho para professores em $\mathrm{TI}$, destacou-se no relatório de avaliação que a instituição "dispõe de espaços reservados para alguns professores" (IFPB, 2017b, p. 15). Ficou evidenciada a insuficiência no quantitativo dos espaços, ressaltada pela sinalização da gestão do curso sobre a elaboração de um novo bloco na instituição, como alternativa viável para implementação de novas salas para todos os docentes em TI.

No instrumento de avaliação aplicado para este relatório considerava-se como critérios de análise os aspectos referentes à "disponibilidade de equipamentos de informática em função do número de professores, dimensão, limpeza, iluminação, acústica, ventilação, acessibilidade, conservação e comodidade" (Inep, 2015, p. 28). Pela análise do relatório não é possível especificar quais aspectos do instrumento apresentam possíveis limitações para a obtenção de conceitos de maior valor.

Ao indicador de desempenho 3.2, espaço de trabalho para coordenação do curso e serviços acadêmicos, o relatório demonstrou que o campus João Pessoa, sede do BAP, oferecia espaço para a coordenação compartilhado com outros cinco cursos pertencentes à UAG. O registro do compartilhamento do espaço de coordenação indica um dos potenciais fatores de limitação que não permitiram, na avaliação, a obtenção dos conceitos 4 ou 5

O instrumento de avaliação aplicado ao BAP identificava os aspectos da "dimensão, equipamentos, conservação, gabinete individual para coordenador, número de funcionários e atendimento aos alunos e aos professores" (Inep, 2015, p. 28). O relatório evidencia apenas os equipamentos disponibilizados à coordenação do BAP, entre os quais ramal telefônico específico, materiais de escritório, impressora multifuncional e notebook exclusivo.

Em relação ao objeto de análise sala de professores, presente no índice 3.3 , o relatório afirma que a sede no campus João Pessoa "dispõe de um espaço reservado para os professores com $40 \mathrm{~m}^{2}$, com uma mesa grande para reunião, boa iluminação, armário para guardar pequenos objetos, banheiro e quatro computadores ligados" (IFPB, 2017b, p. 15).

No instrumento de avaliação aplicado para a avaliação do BAP foram considerados os aspectos da "disponibilidade de equipamentos de informática em função do número de professores, dimensão, limpeza, iluminação, acústica, ventilação, acessibilidade, conservação e comodidade" (Inep, 2015, p. 29). Identifica-se, em geral, que os aspectos propostos estão inseridos no relatório, mas sem especificações diretas que permitam reconhecer potenciais limitações de cada ponto destacado.

Último indicador considerado como fraqueza e ameaça na dimensão 3, o índice 3.4, aborda a avaliação das salas de aula. O relatório destacou que as salas de aula disponibilizadas possuíam capacidade média para quarenta discentes, contendo equipamentos tecnológicos para as atividades de ensino - computador, som e data show e atendendo com suficiência os aspectos da "limpeza, iluminação, ventilação, acústica, conservação e comodidade" (IFPB, 2017b, p. 16). 
O instrumento de avaliação aplicado ao BAP identificava as "quantidades e número de alunos por turma, disponibilidade de equipamentos, dimensões em função das vagas previstas/autorizadas, limpeza, iluminação, acústica, ventilação, acessibilidade, conservação e comodidade" (Inep, 2015, p. 29). Nota-se que, em geral, os aspectos foram abordados no relatório de avaliação do BAP.

É importante destacar, frente aos indicadores de desempenho avaliados como fraquezas e ameaças na dimensão da infraestrutura, e em especial às salas de aula, que o BAP, como curso de modalidade EAD, segmenta-se entre sua sede e polos. Na sede, situada no IFPB campus João Pessoa, estão localizados os espaços relativos aos gabinetes de trabalho para professores em $\mathrm{TI}$, coordenação do curso e sala de professores. Em referência aos polos, o BAP oferta duzentas vagas em quatro polos UAB no Estado da Paraíba, localizados nos municípios de Alagoa Grande, Araruna, Lucena e Mari, proporcionando cinquenta vagas em cada localidade. Portanto os espaços utilizados para as atividades presenciais do BAP podem ser realizados, tanto em sua sede, quanto nos polos.

De acordo com o panorama apresentado os indicadores apresentados à dimensão 3 podem ser considerados como ameaças, devido a manutenção dos espaços acadêmicos e pedagógicos estarem amparados sob a gestão do curso, localizado no IFPB campus João Pessoa, e de fraquezas, por integrar ao planejamento e gestão do BAP o desafio em pleitear e buscar soluções sobre esses aspectos junto à UAG, à direção-geral do campus e aos órgãos municipais ao qual está integrado.

Em relação aos pontos fortes, na dimensão da infraestrutura, apenas o objeto de análise sobre a instituição do CEP obteve o conceito máximo. Os indicadores concernentes à disposição de equipamentos de informática aos discentes, bibliografia básica, bibliografia complementar e sistema de controle de elaboração e distribuição de material didático foram considerados muito bons, de acordo com a demanda já existente.

A identificação das forças, fraquezas, oportunidades e ameaças, como representado nas três matrizes elaboradas por meio da ferramenta da análise Swot, torna-se uma estratégia em potencial voltada para contribuição à gestão do BAP, auxiliando o planejamento de ações voltadas para a melhoria dos processos avaliativos a serem realizados no curso, em especial o de renovação de reconhecimento.

\section{Considerações finais}

Buscou-se evidenciar a inserção da avaliação da qualidade da educação superior dentro do panorama histórico das políticas públicas educacionais, em especial às políticas de supervisão de instituições e dos cursos ofertados resultando na criação do Sinaes, no ano de 2004, pelo MEC.

O observou-se as particularidades sobre a avaliação dos cursos de graduação, evidenciando a aplicação do IACG e os conceitos obtido por seus indicadores de desempenho no processo avaliativo, resultando na elaboração de relatório de avaliação externa in loco, responsável por subsidiara autorização, o reconhecimento e a renovação de reconhecimento dos cursos. Incluído a essa perspectiva foram investigadas as relações do BAP com a avaliação de cursos, constatando-se que o curso obteve seu reconhecimento em 2017 com a realização de procedimento avaliativo e publicação de relatório de avaliação externa in loco.

ก. 19

e65770, p. 1-13

2021 
Com o objetivo de identificar estratégias para a gestão do BAP sobre os desafios que o curso terá frente aos próximos ciclos avaliativos, demonstrou-se o uso da análise Swot em relação aos conceitos obtidos pelos indicadores de desempenho presentes no último relatório de avaliação externa in loco. Foram definidos como ameaças e fraquezas cinco indicadores identificados com o conceito 3 - menor valor obtido no relatório de avaliação - organizados e analisados por meio de matrizes Swot: material didático institucional, gabinetes de trabalho para professores em TI, espaço de trabalho para coordenação do curso e serviços acadêmicos sala de professores e salas de aula.

A identificação e organização dos pontos fracos e fortes do BAP, levando em consideração as atribuições dos ambientes interno e externo do curso, torna-se um potencial facilitador na elaboração de estratégias de gestão, em especial às ações voltadas para a melhoria das fraquezas e ameaças presentes nos indicadores de desempenho que obtiveram o conceito 3 .

Tendo em vista a influência da avaliação externa sobre a gestão dos cursos de graduação do país, entre eles o BAP, torna-se essencial destacar estratégias como a análise Swot, voltadas a contribuir às especificações determinadas pelo Sinaes e pelos procedimentos avaliativos elaborados pelo Inep, como uma atividade indispensável para manutenção da continuidade de suas atividades.

\section{Referências}

BRASIL. Lei n. 11.892, de 29 de dezembro de 2008: institui a rede federal de educação profissional, científica e tecnológica, cria os institutos federais de educação, ciência e tecnologia e dá outras providências. Brasília: MEC, 2006. Disponível em: http://www.planalto.gov.br/ccivil_03/_Ato2007-2010/2008/Lei/L11892.htm. Acesso em: 22 out. 2020.

BRASIL. Lei n. 10.861, de 14 de abril de 2004: institui o Sistema Nacional de Avaliação da Educação Superior - Sinaes e dá outras providências. Brasília: Inep, 2004. Disponível em: http://www.planalto.gov.br/ccivil_03/_ato2004-2006/2004/lei/l10.861.htm. Acesso em: 22 out. 2020.

BRASIL. Decreto n, 9.057, de 25 de maio de 2017: regulamenta o art. 80 da lei n. 9.394, de 20 de dezembro de 1996, que estabelece as diretrizes e bases da educação nacional. Brasília: DOU, 2017a. Disponível em: http://www.planalto.gov.br/ccivil_03/_ato20152018/2017/decreto/d9057.htm. Acesso em: 23 out. 2020.

CAVALCANTI, Lourdes Maria Rodrigues; GUERRA, Maria das Graças Gonçalves Vieira. Diagnóstico institucional da Universidade Federal da Paraíba a partir da análise Swot. Revista Meta: Avaliação, Rio de Janeiro, v. 11, n. 33, 2019, p. 694-718.

GUERRA, Maria das Graças Gonçalves Vieira; RIBEIRO, Wagner Leite. Avaliação de cursos a partir do Sinaes: uma análise para melhoria da qualidade na Universidade Federal da Paraíba. Revista Educação em Questão, Natal, v. 57, n. 53, 2019, p. 1-24.

HOFRICHTER, Markus. Análise Swot: quando usar e como fazer. Porto Alegre: Revolução Ebook, 2017.

IFPB. Plano pedagógico de curso - bacharelado em Administração Pública. João Pessoa: IFPB, 2017a.

IFPB. Relatório de avaliação externa do reconhecimento de curso - bacharelado em Administração Pública. João Pessoa: IFPB, 2017b. 
INEP. Instrumento de avaliação de cursos de graduação - presencial e a distância: subsidia os atos autorizativos de cursos - autorização, reconhecimento e renovação de reconhecimento - nos graus de tecnólogo, de licenciatura e de bacharelado para a modalidade presencial e a distância. Brasília: Inep, 2015.

KOTLER, Philip; KELLER, Kevin Lane. Administração de marketing. São Paulo: Pearson Education, 2012.

SANT'ANA, Tomás Dias et al. Plano de desenvolvimento institucional - PDI: um guia de conhecimentos para as instituições federais de ensino. Alfenas: Forpdi, 2017.

SOUZA, Saulo Rodrigo Alves de; GUERRA, Maria das Graças Gonçalves Vieira. Autoavaliação institucional da Universidade Federal da Paraíba: diagnóstico a partir da Comissão Própria de Avaliação. Revista Diálogo Educacional, Curitiba, v. 20, n. 64, 2020, p. 405-433.

Marcos Vasconcelos Paiva é técnico-administrativo no Instituto Federal da Paraíba, campus João Pessoa.

Orcid: https://orcid.org/0000-0003-2361-5967.

Endereço: Avenida Primeiro de Maio, 720 - 58015-435 - João Pessoa - PB Brasil.

E-mail: marcosvpaiva@hotmail.com.

Maria das Graças Gonçalves Vieira Guerra é professora na Universidade Federal da Paraíba.

Orcid: http://orcid.org/0000-0002-6943-0338.

Endereço: Avenida Primeiro de Maio, 720 - 58015-435 - João Pessoa - PB Brasil.

E-mail: gracinhavieira@yahoo.com.br.

Todos os autores conceberam a ideia. Maria realizou a supervisão do planejamento e execução da atividade de pesquisa. Todos os autores discutiram os resultados e contribuíram para a versão final do manuscrito.

Recebido em 13 de maio de 2021.

Aceito em 10 de agosto de 2021.

(c) $(1) \Theta$ 